\title{
ANALISIS KADAR HIDROQUINON PADA LULUR TIDAK BERMEREK YANG DIPERJUALBELIKAN DI KOTA MAKASSAR
}

\author{
Nur Qadri Rasyid ${ }^{1)}$, A. Indah Halwadiyah ${ }^{1)}$ \\ ${ }^{1)}$ Program Studi DIII Teknologi Laboratoriun Medis Politeknik Kesehatan Muhammadiyah Makassar \\ Alamat Korespondensi:nqadrir@gmail.com
}

\begin{abstract}
Abstrak
Hidroquinon merupakan zat berbahaya yang dilarang digunakan, berbentuk jarum halus yang sering digunakan dalam krim pemutih. Pemakaian hidroquinon secara berlebih dapat mengakibatkan gangguan kesehatan seperti menyebabkan iritasi pada kulit dan kanker darah. Penelitian ini dilakukan secara observasi laboratorik dengan tujuan untuk mengatahui kadar hidroquinon pada lulur racikan tidak bermerek yang diperjualbelikan di pasar sentral kota Makassar. Berdasarkan penelitian yang telah dilakukan menggunakan metode spektrofotometer UV-Vis, diperoleh hasil kadar hidroquinon pada lima sampel yaitu A 0.0001\% B 0.0001\%, C 0.0006\%, D 0.0007\%, dan E $0.0001 \%$. Hasil yang diperoleh menunjukkan sampel $A, B, C, D$ dan E mengandung hidroquinon dengan kadar yang rendah, tetapi hidroquinon tidak dapat digunakan pada kosmetik berdasarkan public warning/peringatan nomor KH.00.01.432.6081 tahun 2009 yang menyatakan kosmetik mengandung bahan berbahaya/bahan dilarang termasuk hidroquinon, dimana penggunaan bahan tersebut dapat membahayakan kesehatan dan dilarang digunakan karena hidroquinon termasuk obat keras. Tetapi hidroquinon hanya dapat digunakan berdasarkan resep dokter.
\end{abstract}

Kata Kunci:Hidroquinon, Lulur

\section{PENDAHULUAN}

Zaman modern seperti ini, penampilan yang menarik salah satu syarat mutlak dalam dunia kerja dan pergaulan. Karena kecantikan merupakan hal yang amat penting bagi semua wanita. Selain kecantikan wajah, kecantikan tubuh juga menjadi salah satu hal utama yang perlu diperhatikan dengan seksama. Berbagai metode perawatan perlu dilakukan agar kecantikan selalu terpancar. Salah satunya dengan menggunakan berbagai macam produk perawatan tubuh seperti, sabun, lulur, body lotion, dan parfum. Sehingga seseorang tidak segan-segan mengeluarkan uang secara rutin untuk melakukan perawatan tubuh karena menginginkan kulit putih, bersih, cerah dan enak dilihat (Fauzi dan Nurmalina, 2012).

Sebagian orang yang memiliki kulit gelap lebih memilih melakukan perawatan kulit badan dengan menggunakan sediaan lulur berbahan kimia yang ada dipasaran, dan ada juga yang belum berani menggunakan kosmetik berbahan kimia karena takut dengan efek samping. Dalam memilih produk kosmetik, terutama kosmetik pemutih, perlu adanya sikap hatihati dan teliti, agar tidak terjadi kesalahan yang fatal. Apalagi kosmetik yang banyak beredar di pasaran, terkadang tidak mencantumkan komposisi yang cukup. Sedangkan kosmetik tersebut banyak diminati oleh masyarakat pada kalangan menengah ke bawah karena harganya yang murah dan khasiatnya cepat (Fauzi dan Nurmalina, 2012).

Penggunaan hidroquinon menurut peraturan Badan Pengawasan Obat dan Makanan (BPOM) mengeluarkan surat Public Warning/peringatan No. KH.00.01.432.6081 tanggal 1 Agustus 2007 adalah hidroquinon diatas $2 \%$ termasuk obat keras yang hanya dapat digunakan berdasarkan resep dokter, bahaya pemakaian obat keras ini tanpa pengawasan dokter dapat menyebabkan iritasi kulit, kulit menjadi merah dan rasa terbakar juga 
menyebabkan kelainan pada ginjal, kanker darah dan kanker sel (Puspita et al, 2016). Kemudian hidroquinon menurut Kepala Badan Pengawasan Obat dan Makanan (BPOM) berdasarkan surat Public Warning/Peringatan No. KH. 00.01.432.2503 tahun 2009 tentang kosmetik mengandung bahan berbahaya/bahan dilarang, termasuk hidroquinon, dimana penggunaan bahan tersebut dalam sediaan kosmetik dapat membahayakan kesehatan dan dilarang digunakan. Hidroquinon termasuk golongan obat keras yang hanya dapat digunakan berdasarkan resep dokter. Bahaya pemakaian obat keras ini tanpa pengawasan dokter dapat menyebabkan iritasi kulit, kulit menjadi merah dan rasa terbakar juga dapat menyebabkan kanker darah dan kanker sel hati (Ditjen POM RI, 2009).

Berdasarkan penelitian yang telah dilakukan oleh Irsalina (2016) dari 9 sampel yang diteliti, terdapat 1 sampel yang kadarnya masih memenuhi syarat, sedangkan 8 sampel yang lain kadar hidroquinonnya tidak memenuhi syarat atau tidak sesuai dengan Peraturan Menteri Kesehatan Indonesia No.445/MENKES/PER/V/1998 yang mengatakan bahwa kadar hidroquinon dalam kosmetik diperbolehkan dengan kadar maksimal 2\%. Presentase sampel krim pemutih yang kandungan hidroquinon masih memenuhi syarat adalah $11 \%$, sedangkan sampel krim pemutih yang mengandung hidrokuinon tidak memenuhi syarat adalah $89 \%$ (Irsalina et al, 2016).

\section{METODE PENELITIAN} Alat dan Bahan

Alat yang digunakan dalam penelitian ini adalah Beaker Glass, neraca analitis, erlenmeyer $250 \mathrm{ml}$, pipet tetes, spatula, hot plate, kertas saring, labu ukur $10 \mathrm{ml}$, Spektofotometri , pengaduk kaca, dan gelas ukur.
Bahan yang digunakan dalam penelitian ini merupakan sampel (Lulur), hidroquinon, $\mathrm{HCl} 4 \mathrm{~N}$, etanol, natrium sulfat dan kertas saring.

\section{Prosedur Kerja}

Pembuatan Larutan Uji

Ditimbang sampel masing-masing sebanyak 1,2 gram dimasukkan ke dalam erlenmeyer $250 \mathrm{ml}$ dan masing-masing wadah diberi label. Ditambahkan 6 tetes $\mathrm{HCl} 4 \mathrm{~N}$ dan $10 \mathrm{ml}$ etanol kemudian dipanaskan di atas penangas air sambil diaduk. Kemudian disaring dengan mengunakan kertas saring yang telah berisi dengan 1 gram natrium sulfat dan dimasukkan ke dalam labu ukur $10 \mathrm{ml}$. Ditambah dengan etanol $96 \%$ sampai garis tanda dan dikocok hingga homogen.

Pembuatan Larutan baku hidroquinon 1000 ppm

Ditimbang 0,1 gram hidroquinon kemudian dilarutkan dengan etanol $96 \%$ dengan labu takar $100 \mathrm{ml}$, ditambah sampai garis dan homogenkan.

Pembuatan kurva kalibrasi

Diambil larutan baku hidroquinon 1000 ppm sebanyak $10 \mathrm{~mL}$, masukkan ke dalam labu ukur $100 \mathrm{~mL}$, tambahkan dengan etanol $96 \%$ hingga volume tepat $100 \mathrm{~mL}$. Diperoleh larutan baku hidroquinon dengan konsentrasi 100 ppm. Dibuat larutan baku hidroquinon seri konsentrasi 0,4, 0,6, 0,8, 1, 1,2 ppm.

Pengukuran kadar hidroquinon

Dimasukkan larutan uji ke dalam kuvet pada spektrofotometri UV-Vis pada panjang gelombang 294nm. Dihitung kadar larutan uji dengan rumus persamaan regresi dan kurva kalibras. Sebanyak $1 \mathrm{~g}$ Hidroquinon dimasukkan ke dalam labu ukur $100 \mathrm{~mL}$ dan diencerkan dengan etanol hingga batas sehingga diperoleh larutan hidroquinon dengan konsentrasi $1 \%$ (Puspita et al, 2016). 


\section{HASIL DAN PEMBAHASAN}

Berdasarkan penelitian yang dilakukan di laboratorium riset UIN alauddin fakultas sains dan teknologi Tabel 1. Hasil Analisis Kadar Hidrquionon jurusan kimia. Diperoleh hasil kadar hidroquinon yang telah dilakukan terhadap 5 sampel lulur racikan tidak bermerk yaitu sebagai berikut :

\begin{tabular}{ccccc}
\hline \multirow{2}{*}{ Sampel } & \multirow{2}{*}{ Absorbansi } & \multirow{2}{*}{$\begin{array}{c}\text { Konsentrasi } \\
(\mathrm{mg} / \mathrm{L})\end{array}$} & $\mathrm{mg} / \mathrm{kg}$ & $\%$ \\
\cline { 4 - 5 } & & 1.5551 & 1.2959 & 0.0001 \\
$\mathrm{~A}$ & 0.0728 & 1.1589 & 0.965 & 0.0001 \\
$\mathrm{~B}$ & 0.0541 & 6.9703 & 5.8086 & 0.0006 \\
$\mathrm{C}$ & 0.3284 & 0.8559 & 0.7132 & 0.0007 \\
$\mathrm{D}$ & 0.0398 & 1.0953 & 0.9127 & 0.0001 \\
$\mathrm{E}$ & 0.0511 & &
\end{tabular}

Pada penelitian ini sampel yang digunakan adalah lulur racikan tidak bermerek dilakukan secara purposive sampling didasarkan pada suatu pertimbangan tertentu yang dibuat oleh peneliti berdasarkan ciri atau sifat populasi yang sudah diketahui sebelumnya, lulur racikan ini didapatkan dari lima toko kosmetik berbeda yang berada di pasar sentral kota Makassar. Penetapan kadar hidroquinon pada lulur racikan dilakukan dengan metode Spektrofotometer UV-Vis karena hanya membutuhkan sedikit pelarut, waktu yang singkat untuk analisis, dan dapat menganalisis larutan dengan konsentrasi yang sangat kecil.

Penetapan kadar dilakukan dengan cara ditimbang sampel dan ditambahkan $\mathrm{HCl} 4 \mathrm{~N}$ yang bertujuan agar hidroquinon dapat dipisahkan dari senyawa lain yang ada di dalam lulur. Kemudian ditambahkan dengan etanol yang bertujuan untuk melarutkan hidroquinon kemudian dipanaskan lalu disaring dengan menggunakan kertas saring yang telah berisi natrium sulfat yang bertujuan untuk menarik kandungan air. Selanjutnya hasil penyaringan ditambahkan etanol 96\% sampai garis tanda yang terdapat dalam sampel.

Pembuatan kurva kalibrasi terlebih dahulu dibuat larutan series standar dengan konsentrasi 0,4 ppm, 0,6 ppm, 0,8 ppm, 1 ppm, dan 1,2 ppm. Fungsi pembuatan kurva kalibrasi untuk melihat linieritas antara konsentrasi dengan serapan. Berdasarkan pengukuran antara nilai serapan dan konsentrasi diperoleh persamaan $\mathrm{y}=$ $0,0472 \mathrm{x}-0,0006$. Nilai $\mathrm{y}$ adalah serapan, nilai a adalah slope (kemiringan), nilai $x$ adalah konsentrasi, dan nilai $b$ adalah intercept.

Berdasarkan hukum Lambert-Beer, absorbansi berbanding lurus terhadap konsentrasi dan ketebalan sel. Absorbansi yang didapat dari sampel yaitu sampel A 0,0728, sampel B 0,0541, sampel C 0,03284, sampel D 0,0398 dan sampel E 0,511. Berdasarkan hasil pengujian di ketahui bahwa kadar hidroquinon dalam lulur racikan tidak bermerk yang diperjualbelikan di pasar sentral kota Makassar yaitu Sampel A sebesar 0,0001\%, sampel B $0.0001 \%$, sampel C $0,0006 \%$, sampel D 0,0007\% dan sampel E 0,0001\%. Berdasarkan data yang diperoleh diatas menunjukan bahwa kadar hidroquinon yang ditambahkan dalam lulur racikan tidak bermerek masih dengan kadar yang sangat rendah dan tetapi hidroquinon tidak dapat digunakan pada kosmetik berdasarkan public warning/peringatan nomor KH.00.01.432.6081 tahun 2009 yang menyatakan kosmetik mengandung bahan 
berbahaya/bahan dilarang termasuk hidroquinon, dimana penggunaan bahan tersebut dapat membahayakan kesehatan.

Hidroquinon termasuk obat keras yang hanya dapat digunakan berdasarkan resep dokter. Bahaya penggunaan hidroquinon tanpa pengawasan dokter dengan kadar rendah dapat menyebabkan iritasi kulit, kulit mejadi memerah dan rasa terbakar. Tetapi pada kadar tinggi dapat menyebabkan kelainan pada ginjal, kanker darah dan kanker kulit. Hidroquinon bekerja dengan menghambat total enzim tirosinase sehingga menghambat konversi DOPA (dehidroksil phenil alanin) menjadi melanin. Hidroquinon tidak hanya menghambat pembentukan melanin tetapi juga detktruksi melanin yang baru terbentuk, sedangkan mekanin berperan melindungi kulit dari paparan sinar matahari berlebih (Ditjen POM RI, 2009).

\section{KESIMPULAN}

Berdasarkan hasil penelitian yang telah dilakukan, dapat ditarik kesimpulan bahwa sampel A sebesar $0.0001 \%$, sampel B $0.0001 \%$, sampel C $0.0006 \%$, sampel D $0.0007 \%$ dan sampel E $0.0001 \%$, mengandung hidroquinon dengan kadar yang rendah, tetapi hidroquinon tidak dapat digunakan pada kosmetik berdasarkan public warning/peringatan nomor KH.00.01.432.6081 tahun 2009

\section{DAFTAR PUSTAKA}

Fauzi, A. R dan Nurmalina, R. (2012). Merawat Kulit dan Wajah. Jakarta: Gramedia

Direktorat jendral POM RI, 2009. Public Warning/Peringatan tentang Kosmetik Mengandung Bahan Berbahaya/Bahan Dilarang, Jakarta.

Puspita L, Feladita N dan Saputri, G.A.R (2016). Identifikasi Dan Penetapan Kadar Hidroquinon Dalam Krim Malam Pada Empat Klinik Kecantikan Di Bandar Lampung Dengan Menggunakan Metode KLT dan Spektrofotometer UV-Vis. Jurnal Analis Farmasi, (Online) Vol. 1. Diunduh pada 20 Mei 2018.

Irsalina, D. Astuti, D.W dan Prasetya, H.R (2016). Identifikasi Hidroquinon pada krim pemutih yang dijual di Minimarket Wilayah Minomartani, Yogyakarta. Jurnal of Agromedicine and Medical Sciences, (Online) Vol. 2(1). diunduh pada 9 april 2018. 